\title{
A QUESTÃo DA SAÚde, DA PESQUISA E DO PODER - UM PROBLEMA PARA AS ENFERMEIRAS
}

Tamara Iwanow Cianciarullo*

Nesta última década do século, as doenças decorrentes da pobreza e desnutriçăo ainda năo foram resolvidas de forma satisfatória.

$\mathrm{O}$ alto investimento em tecnologia e na formação de recursos humanos não tem apresentado um resultado que se possa considerar adequado ao montante investido, tanto nos países desenvolvidos quanto nos países em desenvolvimento.

A "Saúde para Todos no Ano 2000", um pressuposto aceito por autoridades, profissionais e leigos, na verdade não foi efetivada como programa capaz de modificar a realidade vigente na área da saúde. Faltam ainda recursos humanos, sistemas de educaçăo popular e infra-estrutura para desenvolvimento da ciência e da tecnologia apropriadas, principalmente nos palses em desenvolvimento.

A mortalidade infantil e materna, a desnutriçăo, as doenças infecciosas e parasitárias, $o$ abandono de pessoas idosas, o avanço das doenças consideradas de primeiro mundo como a AIDS, as doenças cardiovasculares, a hipertensão, o câncer e os acidentes de tráfego constituem problemas de saúde importantes em nosso País.

Estes problemas têm sido abordados por meio de programas específicos vinculados eminentemente à formação de recursos humanos, ao desenvolvimento de tecnologias especificas facilitadoras na realização de diagnósticos precoces e na assistência curativa. A evolução da investigação científica tem se voltado para a cura.

Proporcionalmente, muito pouco se tem feito em relação à assistência primária, desenvolvimento de um compromisso pessoal ou grupal, definiçáo de responsabilidades leigas e profissionais em relação à saúde, desenvolvimento de tecnologias simplificadas capazes de produzir resultados adequados com pequenos investimentos e gerar novos conhecimentos fundamentados em processos reais cotidianos

A reorientação de equipes de saúde, a mobilização de líderes comunitários, e a priorização da descentralização do saber e do poder de decisão em relaçáo ao processo do cuidado são principios importantes para as enfermeiras.

As enfermeiras estão conscientes de que nos proximos anos ocorrerá uma sensível mudança do cuidado institucional para o cuidado desinstitucionalizado, e estão se preparando para esta mudança.

\footnotetext{
- Enfermeira. Professor Titular e Diretora da Escola de Enfermagem da Universidade de São Paulo.
} 
Desenvolver uma base cientifica para promoção da saúde é competência de equipes multiprofissionais, mas desenvolver e implementar uma base científica para o cuidado de enfermagem é de competência exclusiva da profissional enfermeira. Esta vem desenvolvendo pesquisas e ampliando os seus resultados cada vez mais nas últimas décadas, buscando soluções conjuntas para os problemas de saúde do indivíduo, de grupos específicos e da comunidade, por meio da utilização de estruturas cognitivas e de teorias desenvolvidas e validadas por seus pares.

\section{A enfermagem vista como ciência}

Quando enfermeiros elaboram conceitos, bem como produzem novas idéias articuladas com significados para a profissão, estão desenvolvendo modelos teóricos. Quando estes modelos são testados e validados por meio de ações praticadas em situações concretas estão produzindo novos conhecimentos em enfermagem.

Os conceitos fundamentais para a enfermagem centralizam-se cada vez mais no cuidado, reconhecido como o cerne, a essência da enfermagem.

Conhecimentos articulados de forma sistematizada e organizada, na enfermagem, sugerem, segundo OREM (1991), uma necessidade de se centralizar a estrutura substantiva e sintática dos conhecimentos de enfermagem, visualizando-a como uma ciência prática.

Esta nova visão traz de volta, para a enfermagem, um enfoque prático, porém com forte suporte científico, objetivando, o desenvolvimento de uma nova área do saber científico: a ciência da enfermagem, enquanto "ciência do cuidado". Este enfoque caracteriza-se por aquisição de conhecimento consciente e intencional e por organização dos seus componentes, logicamente interrelacionados, a fim de ser alcançado um objetivo prático (BOTTORFF, 1991).

Esta visão afasta de forma concreta o conhecimento da enfermagem de uma subclasse do saber biomédico e define uma área de competência específica, "a cuidativa", provendo ao enfermeiro, espaços específicos de competência, de capacidade para o desenvolvimento profissional e definição do âmbito de sua ação, sem desprezar as outras formas de saber provindas de outras áreas, denominadas neste contexto de ciências aplicadas à enfermagem.

Esta visão da enfermagem e do saber da enfermagem, voltada para a prática provê os enfermeiros de influência sobre o seu próprio "fazer", determinando a direção da educação, da pesquisa e da sua prática. Define, ainda, a perspectiva de um outro participante do cuidado: o cliente, a família ou a comunidade, cada vez mais ativos e exigentes, em relação aos serviços que utilizam.

Estes têm plena consciência de que os custos, o acesso e a qualidade dos serviços de assistência aos quais têm direito estão cada vez mais distantes das suas necessidades, possibilidades e anseios. A questáo que se coloca neste contexto é se as enfermeiras têm se preparado e instrumentalizado o suficiente para participarem efetiva e eficazmente deste processo de buscar soluções para os problemas de saúde da coletividade em seu âmbito de ação; se elas têm respondido à demanda pelos nossos serviços com competência quantitativa e qualitativa e, se os estudos e as pesquisas por elas realizadas, provocam impacto e geram mudanças nos serviços prestados à população.

Ao respondermos a estas questões estaremos sedimentando definitiva- 
mente, não apenas as relações ccm a nossa clientela mas a nossa inserção formal no rol das profissões, afastando-nos definitivamente do contexto das chamadas semiprofissões.

\section{A pesquisa}

A resposta às necessidades e anseios da sociedade, no que diz respeito à demanda de serviços de enfermagem, tem em seu contexto o pressuposto das habilidades e dos conhecimentos especificos postos em prática e da responsabilidade pelos resultados da sua utilização.

O primeiro refere-se ao proprio domínio do saber e do fazer profissional, quando a enfermeira utiliza conhecimentos disponiveis em diferentes áreas e os aplica com competência na aquisição de novos conhecimentos, reorganizados em torno de fenomenos por ela considerados importantes e segue colocando-os à disposição da sociedade.

Estes novos conhecimentos são gerados por um processio que chamamos de pesquisa, e este não é novo na enfermagem. Iniciou-se em 1854 com o estudo epidemiologico de Florence Naghtingale. No Brasil, podemos afirmar que as pesquisas tiveram sua evolução associada à implantação dos cursos de pós-graduação em nível de Mestrado e Doutorado (CIANCIARULI.O \& SALZANO, 1990), mantendo-se sua produção centrada nos docentes e na região sudeste do País.

Cabe, no entanto, destacar não podermos afirmar que toda esta produção do saber na enfermagem brasileira tenha influenciado e modificado a prática, fato que tem orientado o corpo docente da Escola de Enfermagem da USP, nas suas iniciativas de promover reunioes como esta.

A diminuição do espaço virtual existente entre os pesquisadores e os usuários dos resultados das pesquisas, e a diminuição do espaço temporal relacionado à divulgação dos resultados das mesmas constituem uma preocupação das enfermeiras brasileiras.

Além disso, o estabelecimento de canais de comunicação eficazes entre estes os usuários e os pesquisadores transformaram-se em objetivos principais no contexto das enfermeiras preocupadas com a sua função social de melhorar as condições de saúde da população, principalmente a desfavorecida.

Desmistificar e desentronizar a pesquisa torna-se necessário e premente para o desenvolvimento maior da profissão. Arcabouços perenes e distantes das necessidades dos nossos pares, os enfermeiros assistenciais, que lidam diretamente com o produto das pesquisas no cotidiano do "fazer" enfermagem, são razões suficientes para reestudarmos nossas relações. As condições de saúde, assim o exigem.

Por outro lado, o sistema educacional necessita incorporar e explorar melhor a forma, o conteúdo e as estratégias para implementar o ensino dos métodos de investigação nas estruturas curriculares vigentes, visando maior desenvoltura dos enfermeiros nos métodos sistematizados de resolução de problemas.

Se articularmos as necessidades expressas da sociedade quanto aos cuidados de enfermagem à produção dos serviços com qualidade garantida e à produção de pesquisas capazes de melhorar a prática, certamente estaremos em posição de produzir impactos de reconhecida importância e utilidade sobre o sistema de saúde do País. 
Alguns autores afirmam que as enfermeiras sempre tiveram poder, decorrente do conhecimento de que os serviços prestados são essenciais para a sociedade. Outros afirmam que, elas náo valorizam este poder ou ainda não adquiriram, habilidades para alcançá-lo (MOLONEY, 1986).

Em se considerando que, além destes aspectos as próprias enfermeiras, referindo-se ao contexto do poder, têm se posicionado como desprovidas de poder em determinados cenários, esta situação nos parece crucial.

O poder é aqui visualizado sob a ótica do potencial de influência fundamentado em experiencia, habilidades e conhecimentos e sob este aspecto, as bases do poder dependem de variáveis contextuais que as enfermeiras precisam aprender a identificar e dominar para conseguir se posicionar com firmeza, conviç̧ão e segurança.

Por outro lado, tem sido identificadas, também, freqüentemente, situações no contexto das instituições de assistencia e de educação superior, onde a discrepancia entre as responsabilidades e o poder constituem problema de tal monta que se refletem diretamente sobre a autonomia da profissão, ou melhor, sobre a autonomia dos profissionais, perpetuando-se a histórica submissão ao poder de outrem.

Podemos afirmar que estamos inseridos em um contínuo processo de desenvolvimento de habilidades, conhecimentos e experiências, articulando a evolução tecnológica e cientifica da humanidade, mas continuamos com limitados ámbitos de influência no contexto da saúde. É demonstrando nossa capacidade na prática que conquistaremos o poder.

\section{REFERÊNCIAS BIBLIOGRÁFICAS}

BOTTORFF, Y. L. Nursing: a practical science of caring. Adv. Nurs. Sci, v. 14, n. 1, p. 26-39, 1991.

CIANCIARULLO, T. I.; SALZANO, S. D. T. Nursing and nursing research in Brazil. IN: TASK FORCE ON INTERNATIONAL NURSING RESEARCH, Geneva, 1990. Nursing research worldwide: current dimensions and future directions. Geneve, National Center for Nursing Research - International Council of Nurses, 1990. p. 139-49.

MOLONEY, M. M. Profissionalization of nursing: currents issues and trends. Philadelphia, J. B. Lippincott, 1986. $316 \mathrm{p}$.

OREM, D. F. Nursing concepts of practice. Saint Louis, Mosby Year Book, 1991. 